\title{
Amours et colères
}

\author{
Nadia Ghalem
}

The excerpt from the following poem by Nadia Ghalem regards Algeria. Do stifled voices and spurned bodies not deserve to emerge from silence? In order for justice to be done, in order for the eyes that have witnessed the massacres to speak the horror which Algeria has lived through over the past decade, the speaker stands "bare hands / in front of the torturer / chanting a prayer / knife against skin." It is no longer possible to kill in the name of religion.

Colères étouffées

nul espoir à l'horizon

elle est perdue la maison

et règne la peur

la mère n'a plus de pleurs

amour enfant adolescent

torturé en 1988

pour avoir osé crier

dans les rues de la cité

les spasmes de l'hippocampe

la lente respiration de l'univers

l'africanité tanguant des hanches

et le cri silencieux du danseur.

Dans le ventre du continent

un million de réfugiés

en quête d'une terre d'asile

la forêt referme ses bras

le chagrin dans les ports

les bateaux en partance

l'étoile barbaresque

sombre dans les voiles 
corps échoués sur la plage

exténués d'amour

pendant que la bataille fait rage

aux alentours

tu as vu la mort

de tes yeux adoucis

tu t'étonnes de durer

le crime a déjà été commis

dans tes veines le silence

des marées humaines

dans ton pays on tue à la main

la rumeur des gorges

toute la soif de tous les déserts

humblement

cou tendu au bord du gouffre

chair fragile morsure de métal

le travail patient

de l'eau sur le rocher

le lent désespoir du réfugié

le ciel se déchire, dupé

la mer morte

au paysage ravagé

longue plainte

à l'âme écorchée

regard incandescent

la main vers le désert

tendue désespérément

la fille des nomades est partie

les colonnes de réfugiés

aux postes frontières

la route est longue

tout est silence 
femmes enfants et vieillards

marcher au hasard

la faim aiguise la soif

les chanteurs rapent en silence

l'orchidée d'or

déchire ses pétales

sur un éclat de cristal

qui s'ouvre encore

le froid au centre-ville

petite neige d'automne

rien il ne viendra rien

à l'horizon de l'espoir

corps orphelin

vertigineuse solitude

chape du quotidien

c'est déjà le matin

en exil de la langue

des fleurs d'oranger

et de la citronnelle

le froid sur la peau glacée

à main nues

face au bourreau

psalmodiant une prière

couteau contre chair

l'érection mielleuse

face à la nuit

de quelques nébuleuses

où le temps s'enfuit

ton corps

cette muraille

par delà la mort

tes tendres entrailles 
l'ultime liberté

tombée

le couteau est là

la main s'en est emparée

ils récitèrent la prière

en lacérant les chairs

il suffit d'un tout petit moment

et $c^{\prime}$ est la mort du père

les étoiles se mirent au soleil

la lumière de luxe baigne les amants

la nuit bleue fait silence

près de la chandelle un papillon danse

voleur de fleur

voleur d'âme

le premier sera condamné

le second ignoré

le feu du soir

embrase les fagots

le bois innocent

lui ouvre son coeur

dans la chute de tes reins

j'ai vu des caravanes d'Afrique

un bateau sans Amérique

le col d'une chamelle au matin

corps glissant l'un sur l'autre

étreinte mortelle

bataille désespérée

pour l'éphémère fusion

la clé est perdue nul mot ni regard

pour te reprendre dans mes filets

perdus dans l'univers

nous n'avons que nos amours 
pour défier le temps

vol diaphane de phalènes

une échelle pour monter aux étoiles

une écharpe de nuages

de l'or dans nos pas

et l'amour qui s'en va

des musiques s'élèvent

il y a un chant là-bas

trêve fin des combats

et le regard

le regard de l'enfant soldat

apprendre l'oubli

de pays en pays

la mémoire

aquarium endormi

la délégation va discuter

le sort des réfugiés

ils marchent par milliers

leurs gestes sont fatigués

foudre dans le paysage

et marcher

le combat fait rage

ne pas tomber

trois heures du matin

la faim la soif

d'abord le sommeil

puis plus rien 